INASA TEchnical Memorandune 82781

\title{
Design Practices for Controlling Spacecraft Charging Interactions
}

\author{
(NASA-TA-82781) DESTGN PRACTICES FOR \\ CONT ROLL ING SPACECRAFT CHAEGING INTERACTIONS \\ (NASA) 21 P HC A02/MF AOI \\ CSCL $22 B$
}

N82-18311

G3/18 Unclas

\section{N. John Stevens \\ Lewis Research Center \\ Cleveland, Ohio}

\section{Prepared for the}

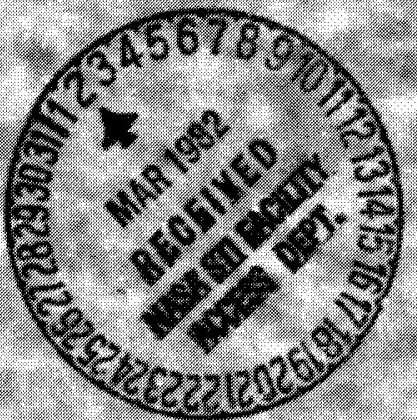

Twentieth Aerospace Sciences Meeting sponsored by the American Institute of Aeronautics and Astronautics Orlando, Florida, January 11-14,1982

\section{Ninsh}


by $N$. John Stevens

\author{
National Aeronautics and Space Administration \\ Lew is Research Center \\ Cleveland, Chio
}

\title{
SUMARY
}

A design guidelines handbook is being prepared to provide criteria for assessing and minimizing spacecraft charging interactions. An evaluation philosophy of analyzing specific satellite designs in a substorm environment specification with MASCAP is proposed. Criteria for possible discharges are given and a technique for computing the discharge transients is outlined. The charging of a three-axis stabilized satellite is examined to illustrate the philosoply. Possible discharge locations are found and transients computed. The effect of charging selected surface coatings is evaluated and found to substantially reduce changing levels.

\section{INTRODUCTION}

In the early 1970's it was pointed out that the geomagnetic substorm environment was charging geosypcbronous satellites strongly negative relative to the sface plasma potential. $1-3$ Subsequent investigations have shown a correlation between this charging and previously unexplained anomalous electronic switching of satellite systems. 4 While most of these al.malous events could be classified as nuisances and were correctable, ont was catastrophic resulting in the loss of the satellite. The onset of these electronic anomalies seems to be correlated with the transition from latching re?ay logic to computer-level logic in satellite systems.

These events indicated that there was an interaction between a supposedly benign environment and satellite systems that could influence mission life. The interaction involved a technology that was not understood. Therefore, an interdependent US Air Force - NASA spacecraft charging investigation was undertaken ${ }^{5}$ to provide guidelines and techniques for controlling the absolute and differential charging of satellite surfaces. One of the principal outputs of this investigation is d Design Guideline Handbook which will compile available ground technology and flight data into a form usable by designers.

The Handbook was first formulated two years ago on the basis of reviews with spacecraft contractors and from available data. ${ }^{6}$ The Handbook was circulated for a limited review and comments incorporated. ${ }^{7}$ The prinicpal factor delaying the formal publication of this $\mathrm{Handbook}$ was the lack of a clear breakdown criterion - a guideline to tell designers when to expect problems, Recent experimental data seems to support viable discharge mechanisms ${ }^{8-10}$ which allow establishment of preliminary criteria for breakdowns on satellite surfaces. Hence, it is possible now to issue a provisional version of the Handbook which can be updated when additional information is available. In this paper, the content of the Handbook is described and specific guidelines are discussed. As an illustrative example of the use of these guidelines, the charging - discharging characteristics of a 3-axis stabilized satellite are evaluated. 
Description

The ou jective of the Design Guideline Handbook is to provide $\mathrm{cr}$ iteria for satellite de:igner's considerations in assessing and controlling environmental charging effects. It is intended to be analogous to thermal designer's handbooks 11 - to be informative, to provide design philosophy and to illustrate techniques to reduce environmental interactions. Since the Handbook is intended for genera' considerations rather than specific designs, it does not treat unique configur ation dependent problems, e.g., discharge pulse coupling into harnesses.

In its present form the Handbook is divided into three ma in parts:

guidel ines to assess charging interactions, guidelines to minimize charging effects, and illustrative eiamples. The guidelines to assess charging are based on the use of analytica: modeling techniques with a recommenced environmental specification. Any matei ial properties needed for the analys is can be obtained from simple charging tests in available facilites. 12 The second part of the Handbook is subdivided into two sections: guidelines for overall satellite designs and subsystem guidelines. The overall guidelines refer to such topics as filtering, shielding, materials selection and active charge control techniques. The subsystem guidelines are a series of detailed do's and don't's for each of the major spacecraft subsystems. The third part of the Handbook is devoted to examples illustrating design techniques for generalized operational satellites (e.g., 3 axis stabilized, spinner, and spinner with despun antenna) and a specific scientific satellite (Galileo).

The basic design philosophy proposed in the Handbook is to use the NASA charging Analyzer Program (NASCAP) $3-16$ to evaluate a given design. This is to be done in a preliminary fashion to isolate possible discharge sites by computing charging beinavior for a few time steps (about half-dozen 100 second time steps should be sufficient). The illustrative example section has been incorporated to point out areas where discharges could occur. Surface charging can be minimizad by materials selection and re-evaluation. The final choice of exterior materials must be an iterative process since both thermal and electrostatic requirements must be considered. Qualification for electrostatic surface cleanliness should be conducted by analysis for both substorm conditions. Testing can be limited to the determination of any unknown paroperties of materials selected. As part of the charging analys is, the designer should evaluate the impact of possible surface discharges on systems performançe. This can be done with one of the avilable coupling codes (e.g., SEMCAP). 17

This philosophy considers only surface charging and possible discharges. There exists also the possibility of discharges due to the high energy particle charging of interior cables. 18 The only protection from this type of breakdown transient is heavier shielding or filtering.

\section{Design Environment}

To assess spacecraft charging interactions, it is necessary to have a :oecification for the geomagnet ic substorm environment in terms that are compaiible with available analytical tools. For this handbook a specification basec on an ATS-5/6 statistical summary has been developed. 7 This specifi- 
cation (see Fig. 1) does not have the characteristics of a real substorm but will produce a maximum stress with in dielectrics.

The specification is given in terms of a single Mariwlian temperature for severe and moderate substorms. This temperature description was chosen because previous analys is of satellite surface charging showed that single Maxwellian enyjronments, although not as realistic as the double Maxwellian descripticns, 19 produced more severe charging. The time curve runs out to oniy $\mathbf{4 0 0 0}$ hours since beyond that time particle temperatures drop below levels that produce charging. The ion temperature (in kV) yas found to be numerically equal to 10 times the electron density (in $\mathrm{cm}^{-3}$ ). To account for the ion composition of the substorm environment, which jndicates a substantial oxygen ion population in addition to hydrogen ions, 20 the ion density is set to be one-third of the electron density.

From this specification an environment for evaluating satellite designs can be obtained (see Table 1). It is recommended that both sunlight (at an angle of incidence to maximize differential charging) and eclipse charging be evaluated. Qualification of a design should be conducted for both moderate and severe substorm environments. Initial assessment of a design can be acne with a single environment to minimize computer time.

\section{Assessment of Charging Interactions}

The assessment of charging behavior oi any satellife design is to be conducted with the NASA Charging Analyzer Program (NASCAP) $13-16$ and the design substorm environment specification. The NASCAP code has the capability of treating both three-dimensional effects, which are important in accurately predicting surface voltages 21 and the transient effects required by the environment specification. Circuit analys is models ${ }^{22-23}$ used in some

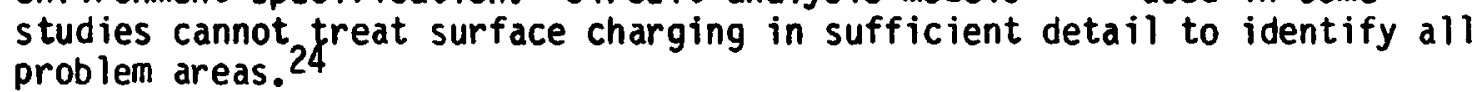

In assessing the impact of environmental charging, the designer must consider several factors. First, is the recognition of the impontance of types of charging, absolute or differential. For absolute charging, the satellite potential charges as a whole - the dielectric surface voltages are "locked" to the ground voltage. This type of charging occurs very rapidly (fractions of seconds) during eclipse charging events, but slowly in sunlight charging. 25 Differential charging usually occurs slowly (minutes) and results in one part of surface being charged to a potential different from other parts of the satellite. This differential charging changes the absolute charging level of the satellite.

Second is the effect of satellite configuration on charging behavior. A spinning satellite usually has a low spacecraft ground potentials (fe hundred volts) in sunlight charging events with the charging controlled primarily by the large areas of body mounted solar arrays. Any shaded dielectric can have large differential voltages induced. A three-axis stabilized satellite can have large negative spacecraft ground potentials (few thousand volts) in sunlight charging environments. The dominant ares controlling charging in this case are the backs of the solar array wings. For both configuratjpns differential charging is limited by the three-dimensional barrier effect.21 In eclipse charging cases the voltage buildup is controlled by the secondary yield of the dielectrics. This discussion is based on an assumed isotropic environment. The effects of anisotropic fluxes are currently being evaluated and these fluxes may influence charging concepts. 
Third is the influence of the mission of the satellite on the extent to which one must control charging interactions. For a scientific satellite absolute charging is usually not cesired. Conductive coated dielectrics are employed to minimize all surface charging and active charge control devices must be incorporated to maintain the spacecraft close to the space plasma potention. Nonscientific satellites, on the other hand, can function while charged. Hence, differential riharging effects should be controlled. The extent to which charging contrcl techniques are employed depends upon project trade-offs.

\section{Environmentally-Induced Surface Breakdowns}

Under geomagnetic substorm conditions satellites are charged to conditions where breakdowns occur. Based on the current state of knowledge provisional criteria for breakdown conditions can be postuiated. These breakdowns are assumed to occur when either:

(a) dielectric surface yoltages are +500 volts relative to an adjacent exposed conductor 8 - 18 .

(b) dielectric-exposed conductor interface has an electric field greater than $1 \times 10^{5}$ volts $/ \mathrm{cm}^{2} 27$

Gaps, seams, edges, and imperfections enhance the existence of these conditions and thereby increase the probability of breakdowns.

For a complete evaluation of a design, discharge transient hazards to spacecraft systems should be ascertained. This requires knowledge of a discharge process. The following process is postulated to provide a calculable indication of such transients. These transients would be the impulses into a satellite from a surface breakdown and can be used for further coupling computations.

The discharge process proposed is that charge is transferred from the satellite to space; in essence satellite to space plasma ground is temporarily shorted. (see Fig. $2(a)$ ). It is assumed that a breakdown continues until the satellite ground potential approaches space plasma potential (as indicated by ground simulation experiments ${ }^{28}$ ). Accompanying this voltage transient is a local collapse of differential voltages at the discharge site. Charge is not drained off of large areas of dielectrics as previously assumed, 29 but some small fraction of the total stored charge is assumed to be lost to space in this differential voltage collapse. The remaining charged dielectrics force the ground potential to return rapidly towards its precharged value.

Discharge transients can be computed as follows:

(1) The square wave approximation of the voltage transient is assumed to be the satellite grand potential at the time of discharge over the discharge period. This period is calculated below (see item $2 \mathrm{C}$ ).

(2) The square wave approximation for the current transient is derived from the total charge lost over the same period. This charge lost is made up of two parts: 
(a) The charge lost to space through the satellite to space capacitor is computed from (see Fig. $2(b)$ ):

$$
\Delta Q_{1}=C_{s}\left|v_{0}\right| \text { (Coulombs) }
$$

where $C_{s}$ is the satellite to space capacitor (typically $10^{10}$ farads) and $\left|V_{0}\right|$ is the absolute value of the satellite ground voltage at time of discharge.

(b) In order to compute the charge lost in the dielectric differential voltage collapse, one has to rely on laboratory results obtained from grounded substrate tests. These tests produced discharges which removed charge from large areas of the dielectric surface, but it is believed that the initiation of the transient is the same for floating substrate discharges. For the present, then, charge redistribution and time duration relationships from these tests will be used. Additional testing should be undertaken to obtain data on discharge characteristics with floating substrates.

It is assumed that only 1 percent of the total charge stored on the dielectric surface is involved in this portion of the discharge process. This is an arbitrary assumption made to stress the fact that charge loss is limited to a small dielectric area. Of this one percent, only $1 / 3$ is lost to space; the remaining $2 / 3$ either stays on the dielectric or neutralizes the polarization charge: 30

$$
\Delta Q_{2}=K C_{D}\left|\Delta V_{D}\right| \text { (Coulombs) }
$$

where:

$K$ is the fraction of total charge lost to space $(0.003)$

$C_{D}$ is the dielectric capacitance (farads)

$\left|\Delta V_{D}\right|$ is the absolute value of differential voltage across dielectric (voits)

(c) Hence, the total charge lost is:

$$
\Delta Q_{L}=\Delta Q_{1}+\Delta Q_{2} \text { (Coulombs) }
$$

and the current pulse is:

$$
I=\frac{\Delta Q_{L}}{\Delta t} \text { (Amps) }
$$

The time duration of this pulse ( $\Delta t)$ is not known. The experimental data for grounded substrate tests indicate that the maximum guration is a function of dielectric area from which charge has been removed. 30 Using this relationship, a time duration can be approximated as: 


$$
\Delta t \sim 0.02\left(0.01 A_{0}\right)^{0.5}(u \mathrm{sec})
$$

where $A_{D}$ is the dielectric area in $\mathrm{cm}^{2}$. Again, it should be stressed that this approximation must be verified or revised by conducting precise tests.

All of the voltage values and capacitance to space $\left(C_{s}\right)$ are available from the NASCAP analysis. Dielectric capacitances can be computed from parallel plate formulas using values of dielectric constant and dimensions used in the NASCAP analysis.

As a consequence of this discharge process, one would expect that sunlight charging events would produce less severe discharges than eclipse charging events, since the ground voltages are less. For the same reason, one would expect spin-stabilized satellites would have less severe discharges than three-axis-stabilized satellites in sunlight charging conditions. These expectations must be evaluated by reviewing available data and conducting additional studies.

What has been presented here riust be considered a preliminary attempt to formulate a usable guide for analyzing satellite designs. It is based on the idea that breakdowns occur early in the mission and does not consider any effects of dielectric aging or ground break-up that may occur with time in space.

\section{Charging Control Techniques}

There are various techniques that can be used to control spacecraft charging interactions. In this section the choice of materials, grounding and filtering are briefly discussed.

Choice of materials. - Exterior surfaces on satellites are usually selected for desired therma optical properties to control component temperatures. This has led to use of high resistivity dielectrics (e.g., quartz, Kapton) which can be charged by substorm environments. This situation can be alleviated by a few simple considerations early in the design phase. Charging can be substantiplly reduced if the bulk conductivity of the djelectric can be increased to $\sim 10^{12} \mathrm{mho} / \mathrm{m}$ or surface resistivity reduced to $\sim 10^{12}$ ohms per square. Furthermore, if the charging of only the dominant dielectric areas is reduced, then overall charging levels can be lowered appreciably.

The use of conductive paint, grounded to the structure, is a good means of controlling charging. This paint can be used on the back (shaded) side of 3-axis stabilized solar arrays or on exterior covers of thermal blankets to substantially reduce absolute and differential charging levels.

The use of high secondary yield coatings on metals is ar effective means of raising ground surface voltages thereby controlling charging. This higher yield can be obtained by using surface coatings and alloys. 31 Increasing the secondary yields on dielectrics (e.g., by use of anti-reflective coatings on solar arrays) may not be advisable since it could increase differential charging. Dielectric paints have voltage-dependent resistivities 29 and, if used on metallic substrates, can not be charged to large negative potentials. Thin, transparent conductive films such as indium-tin-oxide can be used to obtain a uniform conductive surface. There may be a high energy particle interaction that must be evaluated before recommending these transparent conductive coatings. 32 
Changes to specific materials should not be made indescriminately. Design changes should be checked analytically to verify that the change did not introduce problems in other areas of the satellite.

Grounding. - The basic guideline here is that all surfaces should be well grounded to the comon electrical ground (usually the structure). An ungrounded surface responds rapidly to the environmental transients and can introduce larger differential voltages.

Dielectric booms should be avoided because they cannot be grounded. Such booms, protruding from the satellite and charging relatively independently, are highly probable discharge sites.

Filtering. - Satellite surfaces are charged by geomagnetic substorm environments and if charged, then there is a finite probability that there can be discharges. This probability rises for extended life missions. The usual guideline suggested for filtering is to eliminate noise with less than a specified duration. On the joint Canadian-American Communications Technology Satellite in-line transmitters and receixers were used that effectively eliminated noise pulses less than 5 useconds. 33 Similar filtering concept have been proposed for circuits that require protection. 34 Hence, filtering is an effective means of preventing circuit disruption and is recommended for critical circuits, whose anomalous switching would disrupt or endanger satellite operations.

\section{APPLICATION OF DESIGN GUIDELINES}

In this section a generalized three-axis stabilized geosynchronous satellite design is evaluated using the stated guidelines. The purpose of this section is to use this example to illustrate and expand on the techniques proposed. As a consequence the satellite has some features that may not exist on real designs.

\section{Satellite Model Description}

The satellite modeled in the NASCAP code is shown in fig. 3 . It is a representation of a three-axis stabilized, geosynchronous, communications satellite consisting of two, large, sun-tracking solar array wings and a central spacecraft body. The overall dimensions are $9 \mathrm{~m}$ across the wings by $2.4 \mathrm{~m}$ across the body. The model has 470 exposed surfaces and each square in the model is $0.3 \mathrm{~m}$ by $0.3 \mathrm{~m}$.

The solar array wings are each $3 \mathrm{~m}$ by $1.8 \mathrm{~m}$. They are modeled as thin, flat plates with $0.015 \mathrm{~cm}(6 \mathrm{mil})$ si?ica cover slides on the sun facing side and $0.010 \mathrm{~m}$ ( $4 \mathrm{mil}$ ) Kapton substrates. This represents a flexible substrate solar array system capable of producing a total power output of about

1 kilowatt. This array is assumed to be nperating such that one wing is at +25 volts with respect to the spacecraft body while the other is at -25 volts when the array is sunlit. In eclipse conditions the array voltages are set to zero. The interconnects between the solar cells are modeled as silver patches (minimum resolution in NASCAP is one surface cell). These metallic patches represent about 10 percent of the total array area which is a reasonable approximation to the actual exposed metallic area.

The spacecraft body is modeled as an octagon $1.8 \mathrm{~m}$ by $1.5 \mathrm{~m}$ deep. On the earth-facing side are two antennas modeled as octagons $0.9 \mathrm{~m}$ by $0.3 \mathrm{~m} \mathrm{high}$. The sides of these antennas are covered by a grounded thermal blanket with 
$0.010 \mathrm{~cm}$ Kapton outer layer. The antenna cover is plain Kapton which can float electrically. On the opposite end of the body is an apogee insertion motor enclosure modeled as an octagon $1.2 \mathrm{~m}$ by $0.6 \mathrm{~m}$ deep. The end is assumed covered by pure aluminum. The rest of the exposed surfaces of the spacecraft body are covered by $0.010 \mathrm{~cm}$ Kapton, $0.015 \mathrm{~cm}$ Silica (OSR simulation) or pure a luminum patches.

The struts holding the solar arrays to the body are modeled as a quasidielectric material (high resistivity but low secondary yields). A probe has alsc been added to the body. This probe has an unspecified purpose and is modeled as having an aluminum tip with the quasi-dielectric body. Furthermore, this probe is assumed to be very weakly capacitively coupled to the body.

\section{Preliminary Charging Study}

As stated in the guidelines, the satellite design is to be subjected to a preliminary evalution using the design environment specification. For this example the moderate substorm environment was used. Twelve minutes of sunlight charging with sunlight incident at $27^{\circ}$ relative to the solar array normal were simulated. For eclipse charging, an additional 12 minutes were calculated. This process assumes a substorm encounter of local midnight and ooes not correct for spacecraft body rotation with time. The charging history of selected surfaces is shown in Fig. 4. At first glance, the charging results do not appear to be too damaging; the antenna covers and probe seem to stay locked at the ground potential in sunlight charging conditions but do deviate from ground voltages in eclipse. This figure lilustrates the differences between absolute and differential charging mentioned previousiv. In sunlight the absolute charging of the satellite proceeds slowly witn the offferential charging of shaded insulators developing slightly faster. When the satellite enters an eclipse charging condition, the absolute charging changes rapidly and any differential voitages developed are maintained. After the absolute charging level is reached, additional differential charging starts.

A detailed review of the NASCAP graphics output indicates areas where discharges may occur. The predicted voltage profiles around the satellite are shown in Fig. 5 for sunlight charging after 12 minutes $(720 \mathrm{sec})$. As shown in the front view the potentials tend to decay from the shaded Kapton $(-5400 \mathrm{~V})$. However, there are inflection points in the arrays and the center of each wing is at a positive potential with respect to ground (a condition which promotes discharges). The gradients from the array edges towards the center are also severe (as indicated by the number of 1 ines grouped in a small area). These solar array differential voltages can be more severe if it is assumed that the cover slides have a high yield mangnes lum fluoride, anti-reflecting coating instead of plain glass. 10 There are also inflection points between Kapton surfaces and both sunlit and shaded OSR's on the spacecraft body.

The side view of this figure indicates a possible problem at the solar array outer ends. Strong gradtents exist and if there is an exposed metilic area, then breakdowns could occur there. On the spacecraft body there are strong gradients at the interface with the apogee motor. However, unless there is a seam or exposed metal edge in the region, the differential voltages are not sufficient to cause dielectric punch-through breakdowns. It should be pointed out that computer graphics tends to average equipotentials over the surface areas even when the surface is a grounded metalilic area. This can 
lead to over looking possible problems. As shown in Fig. 6, the entire end of the motor case is supposed to be at ground potential. Hence, all voltage ilines should terminate on the dielectric edge which produces a strong electric field at this point. This concentration is not apparent in the computer graphics (Fig. 5) and illustrates the need for care and diligence in interpreting computer outputs.

For eclipse charging conditions, the computed voltage profiles at about 800 seconds are shown in Fig. 7. The possible discharge areas are the solar array wing tips, all Kapton-metal interfaces, probe tip - dielectric boom interface and solar array cell - interconnect gaps. Breakdown characteristics can be estimated for both sunlight and eclipse charging conditions by following the procedure given in the discharge guideline. This procedure is applied to a possible discharge involving a single NASCAP cell area on the solar array (positive differential voltage breakdown criteria) and at a Kapton-metal interface (strong negative electric field criteria). These would be the transient characteristics at the discharge site and would serve as inputs to another code to compute system response.

Solar Array Gap Breakdown: The satellite capacitance to space is computed to be $2.1 \times 10^{10}$ farads. The ground potentials are about $-3 \mathrm{kV}$ in sunlight charging corditions and about $-9 \mathrm{kV}$ in eclipse charging conditions. This results in charge losses of $0.63 \mu \mathrm{C}$ and $1.9 \mu \mathrm{C}$ respectively. The capacitance of the block of solar cells in the 0.3 by $0.3 \mathrm{~m}$ NASCAP square is about $2 \times 10^{-8}$ farads and the differential voltage (maximum) is about 500 volts in sunlight and about 1000 volts in eclipse. Under the criteria that 0.3 percent of the charge stored on the dielectric is also lost, then an additional $0.03: C$ should be added for sunlight charging and $0.06 \mu \mathrm{C}$ added for eclipse charging. The resulting total charge lost would be $0.66 \mu \mathrm{C}$ for sun charging and $1.96 \mu \mathrm{C}$ for eclipse charging. The square wave approximtions for the voltage and current transients of this discharge source are shown in Fig. 8 (based on a computed pulse duration of $60 \mathrm{nsec}$ for the assumed one surface cell breakdown) in both sunlight and eclipse conditions.

Kapton-Metal Interface Breakdow:': The charge contribution from the breakdown of the satellite to space capacitor is the same as above. The differential voltage on the shaded Kaptioi is about $2.5 \mathrm{kV}$ for both sunlit and eclipse charging conditions. Since the Kapton capacitance per NASCAP square is about $2 \times 10^{-8} \mathrm{farads}$, the total charge lost to space is $0.78 \mu \mathrm{C}$ for sunlight charging and $2.0 \mu \mathrm{C}$ tor eclipse charging. The voltage and current transients for this discharge are similar to those shown in Fig. 8.

\section{Design Modifications}

The surface charging of this satellite can be reduced substantially by making the following changes:

(1) Coat the back side of the solar arrays with conductive paint and ground paint to structure.

(2) Reduce the Kapton thermal blanket outer layer resistivity by at least three orders of magnitude. This could be done by use of a conductive paint. The antenna covers were not changed. 
(3) Replace quasi-dielectric material used for solar array struts and probe with metal surfaces orounded to structure.

(4) Improve probe systen coupling to structure.

(5) Paint aluminum insertion motor sheet with dielectric paint.

The modified design was analyzed again for sunlight charging in both moderate and severe substorm conditions. The potential distibutions around the satellite for the moderate substorm are shown in Fig. 9. As can be seen the electrical stress have been significantly reduced. The satellite ground is now oniy -250 volts and the solar array voltage gradients have been substantially reduced. There are still voltage concentrations at the shaded OSR's but these are on the order of only 700 volts - well below the breakdown criterta. The use of a dielectric paint on the aluminum (change no. 5) appeared to cause only a 50-volt change. In the severe substorm environment, the satellite ground is predicted to be -380 volts and the most severe stress is about -1.5 kV across the OSR's - still less than breakdown potentials. Hence, with considerations for surface charging and some additional weight, environmental charging of satellites can be significantly reduced. The trade-off is between added weight for surface-charging control techniques or filters io absorb noise and consequences of ignoring charging interactions. The principal hazard associated with charging is transients on command and telemetry lines. These transients can cause electronic switching anomalies (which can cause serious problems if wrong systems are activated) and scrambled data. The longer range hazards have not yet been catalogued but could include increased contamination, component breakdowns or coating degraation.

\section{CONCLUDING REMARKS}

A Design Guidelines Handbook to provide criteria for assessing and minimizing spacecrafi charging effects in geosynchronous satellites is being formulated as a design tool. Data used in this Handbook have been assembled from interviews with spacecraft manufacturers, from results of ground technology programs and from available flight results. Since the technology investigation is still underway, the handbook will be issued in a preliminary version and upoated at a later time.

The Handbook recommends a philosophy of assessing charging impact by analyzing a given satellite design with the NASA Charging Analyzer Program (NASCAP). A design erivironment specification based on actual substorm environments monitored over the past several years is provided for this analysis.

A preliminary criterion for surface voltage discharges is provided. This criteria, based on ground tests, proposes that these discharges are triggered at dielectric-exposed metal interfaces. The conditions under which discharges can occur are positive differential voltage greater than +500 volts or negative electric fields greater than $1 \times 10^{+5} \mathrm{~V} / \mathrm{cm}$. These surface discharges cause a small transient charge transfer to space which results in a voltage transient in the satellite. A method of computing these transients is presented based on the charge lost through the capacitance to space and a fraction of charge stored in the dielectric at the discharge source. This computation resuits in an estimate of the discharge transients at the dis- 
charge site and can be used as inputs for coupling code analysis of structure/ system responses.

With the proper choice of materials, surface charging can be minimized. As an alternate to this approach, systems can be protected by filtering out the transient pulses.

An example of the charging of a three-axis stabilized geosynchronous satellite is presented to illustrate the use of the design guidelines. The andlysis indicates that, under nominal choice of exterior surfaces, discharges are possible. The use of conductive or quasi-conductive paints on the major charging surfaces would result in a s'bstantial reduction in potentials. The resulting voitages are less than breakoown criteria specification even thol'gh some dielectric surfaces were not changed.

The guidelines presented in the Handbook are recommendations for designers' use. The implementation of any of these guidelines should be based on a comparison of added weight required to minimize interactions against potential consequences of ignoring environmental charging. The hazards of allowing charging interactions are electronic switching anumalies (which can be serious), noise on data lines, reduction of scientific experimental results (particle and field data) and possible longer term hazards of enhanced contamination, component breakdown and coating degradation.

\section{REFERENCES}

1. Sharp, R. D.; Shelley, E. G.; Johnson, R. G., and Paschmann, G.: "Preliminary Results of a L ow Energy Particle Survey at Synchronous Altitude," Journal of Geophysical Research, Vol. 75, 1970, p. 6092.

2. Deforest, S. E. and MCI Iwain, C. E.: "Plasma Clouds in the Magnetosphere," Journal of Geophysical Research, V1,7. 76, June 1971, pp. $3587-36 \Pi$.

3. Deforest, S. E.: "Spacecraft Charging at Synchronous Orbits," Journal of Geophysical Research, Vol. 77, Feb. 1972, pp. 651-659.

4. McPherson, D. A.; and Schober, W. R.: "Spacecraft Charging at Hign Altitudes: The SCA:HA Satellite Program," Spacecraft Charging by Magnetospheric Plasmas, A. Rosen, ed., Progress in Astronautics and AeronauEICS, VOT. 4T, N.Y., AIAA, 1976, pp. 15-30.

5. Lovell, R. R.; Stevens, N. J.; Schober, W. R.; Pike, C. P.; and Lehn, Wm.: "Spacecraft Charging Investigation: A Joint Research and Technology Program," Spacecraft Charging by Majnet.ospheric Plasmas, A. Rosen, ed., Progress in Astronautics and Aeronautics, V01. 47, N.Y., AIAA, 1976, pp. 3-14.

6. Kamen, R. E.; Holman, A. B.; Stevens, N. J.; anc Berkopec, F. D.: "Design Guidelines for Control of Spacecraft Charging," Spacecraft Charging Technology - 1978, NASA CP-2071/AFGL TR-79-0082, 1979, Pp. 817-818.

7. Stevens, N. John: "USE of Charging Control Guidelines for Geosynchronous Satellite Design Studies," Spacecraft Charging Technology - 1980, NASA CP-2182, 1981, Pp. 789-801. 
8. Inouye, G. T.; and Sellen, J. M., Jr.: "TDRSS Solar Array Arc Discharge Tests," Spacecraft Charging Technology .. 1978, NASA CP-2071/AFGL

TR-79-0082, 1979, PD. 834-852.

9. Staskus, J. V.; and Roche, J. C.: "Testing of a Spacecraft Model in a Combined Environment Sinulator," Paper presented at 1981 IEEE Annual Conference on Nuclear and Space Radiation Effects, Seattle, WA, July 21-24, 1981, NASA TM-82723, 1981.

10. Stevens, N. J.; Mills, H. E.; Orange, L.: "Voltage Gradients in Solar Array Cavities as Possible Breakdown Sites in Spacecraft-Charging-Induced Discharges," NASA TM-82710, 1981.

11. Rittenhouse, J. B.; and Singletary, J. B.: "SFace Materials Handbook," NASA SP-3051, 1969.

12. Berkopec, F. D.; Stevens, N. J.; and Sturman, J. C.: "The Lewis Research Center Geomagnetic Substorm Simulation Facility," Proceedings of the

Spacecraft Charging Technology Conference, C. P. Pike and R. R. Lovell, eds., AFGL TR-77-0051/NASA TMX-73537, Feb. 1977, pp. 423-430.

13. Katz, I.; Cassidy, J. J.; Mande 11, M. J.; Schneulle, G. W.; Steen, P. G.; and Ruche, J. C.: "T:i: Capabilities of the NASA Charging Anal!'zer Program," Spacecraft Charging Technology - 1978, NASA CP-2071/AFfL TR-79-0082, 1979, Pp. 101-122.

14. Cassidy, J. J. I1I: "NASCAP User's Manual - 1978" NASA CR-159417, Aug. 1978.

15. Katz, I; Cassidy, J. J.; Mandell, M. J.; Schneulle, G. W.; Steen, P. G.; Parks, D. E.; Rotenber, M.; and Alexander, J. H.: "Extension, Validation, and Application of the NASCAP Code," NASA CR-159595, 1979.

16. Katz, I.; Cassidy, J. J.; Mandell, M. J.; Parks, D. E.; Schneulle, G. W.; Stannard, P. R.; and Steen, P. G.: "Additional Application of the NASCAP Code - Vol. 1: NASCAP Extension" NASA CR-165j49, 1981.

17. Inouye, George T.: "Implications of Arcing due to Sapcecraft Charging on Spacecraft EMI Margins of Immunity" NASA CR-165442, 1981.

18. Vampola, A. L.: "P78-2 Engineering Overview," Spacecraft Charging Technology - 1980, NASA CP-2182, 1981, pp. 439-460.

19. Garrett, H. B.: "Modeling of the Geosynchronous Plasma Environment," Spacecraft Charging Technology - 1978, NASA CP-2071/AFGL TR-79-0082, 1979, pp. 11-22.

20. Johnson, R. G.: "A Review of the Hot P lasma Composition Near Geosynchronous Altitude," Spacecraft Charging Technology - 1980, NASA CP-2182, 1981 , pp. 412-431. 
21. Mandell, M. J.; Katz, I.; Schneulle, G. W.; Steen, P. G.; and Roche, J. C.: "The Decrease in Effective Photocurrents due to Saddle Points in Electrostatic Potentials near Differentially Charged Satellites," IEEE Transactions of Nuclear Science, Vol. NS-25, No. 6, Dec. 1978, Pp. 1313-1317.

22. Incuye, George T.: "Spacecraft Potentials in a Substorm Environment," Spacecraft Charging by Magnetospheric P lasmas, A. Rosen, ed., Progress in Astronautics and Aeronautics, Vol. 47, AIAA, 1976, Pp. 103-120.

23. Massaro, M. J.; and Ling, D.: "Spacerraft Charging Results for the DSCS-III Satellite," Spacecraft Charging Technology - 1978, NASA CP-2071/AFGL TR-79-0082, 1979, Pp. 158-176.

24. Stang, D. B.; and Purvis, C. K.: "Comparison of NASCAP Modeling Results with Lumped-C ircuit Analys is," Spacecraft Charging Technology - 1980, NASA CP-2182, 1981, PP. 665-683.

25. Purvis, C. K.; Staskus, J. V.; Roche, J. C.; and Berkopec, F. D.: "Charging Rates of Metal-Dielectric Structures," Spacecraft Charging Technology - 1978, NASA CP-2071/AFGL TR-79-0082, 1979, pp. 507-523.

26. Purvis, Carolyn K.: "Configuration Effects on Satellite Charging Response" AIAA Paper 80-0040, Jan. 1980.

27. Stevens, N. J.; Purvis, C. K.; and Staskus, J. V.: "Insulator Edge Voltage Gradient Effects in Spacecraft Charging Phenomena," IEEE Transactions on Nuclear Science, Vol. NS-25 No. 6, 1978, pp. 1304-1312.

28 Flanagan. T. M.: Denson, R.; Mallon, C. E.; Treadaway, M. J.; and Wenaas, E. P.: "Effect of Laboratory Simulation Parameters on Spacecraít vi ieiectric Dicharges," IEEE Transactions on Nuclear Science, Vol. NS-26, No. 6, 1979, pp. 5134-5140.

29. Stevens, N. J.; Berkopec, F. O.; Staskus, J. V.; Blech, R. R.; and Narciso, S. J: "Testing of Typical Spacecraft Materials in a Simulated Substorm Environment," Proceedings of the Spacecraft Charging Technology: Conference, C. P. Pike and R. R. Lovel,, eds., AFGL TR-7T-0051/NASA TMX-73537, Feb. 1977, pp. 431-458.

30. Aron, P. R.; and Staskus, J. V.: "Area Scaling Investigations of Charging Phencmena," Spacecraft Charging Technology - 1978, NASA CP-2071/AFGL TR-79-GOe?, I979, Pp. 485-506.

31. Chase, R. W.; Gordon, W. L.; and Hoffman, R. W.: "Secondary Electron Emissior. Yield from Aluminum Alloy Surfaces," Ph.D. Thesis, Case-Western Reserve Univ., 1979.

32. Fellas, C. N.; and Richarcison, S.: "Internal Charging of ITO Coated Mirrors," Paper I-5 Presented at the 18th Annual Conference on Nuclear and Space Radiation Effects, Seattle, WA, Juiy 21-24, 1981. 
33. Gore, J. V.: "Design, Construction, and Testing of the Comunications Technology Satellite - Protection Against Spacecraft Charging " Proceedings of the Spacecraft Charging Technology Conference, C. P. P ik $\bar{\theta}$, and R. R. Lovell, eds., AFEL IR-77-0051/WASA INX-735337, 1977, Pp. 773-788.

34. Bower, S. P.: "Systems Aspects of Spacecraft Charging," Proceedings of the Spacecraft Charging Technology Conference, C. P. Pike and R. R.

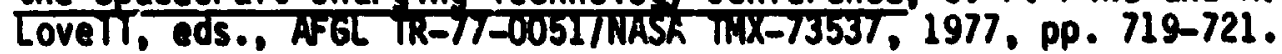

TABLE 1 - DESIGN ENVIRONMENTS

[Single Maxwellian Description]

\begin{tabular}{|l|c|c|c|c|}
\hline \multirow{2}{*}{$\begin{array}{c}\text { Environment } \\
\text { condition }\end{array}$} & \multicolumn{2}{|c|}{ Electrons } & \multicolumn{2}{c|}{ Ions } \\
\cline { 2 - 5 } & $\begin{array}{c}\text { Temp, } \\
\mathrm{keV}\end{array}$ & $\begin{array}{c}\text { Dens ifty, } \\
\mathrm{cm}^{3}\end{array}$ & $\begin{array}{c}\text { Temp, } \\
\mathrm{keV}\end{array}$ & $\begin{array}{c}\text { Dens ițy, } \\
\mathrm{cm}^{3}\end{array}$ \\
\hline Moderate & 8.0 & 2.1 & 21.0 & 0.7 \\
Severe & $1 \mathrm{~J} J$ & 1.1 & 11.0 & 0.4 \\
\hline
\end{tabular}




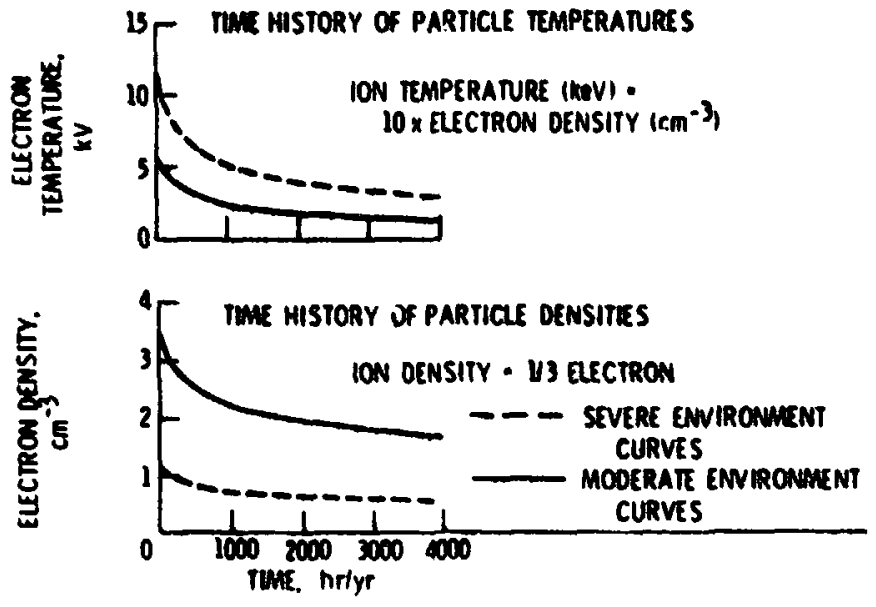

Figure 1. - Seacilication for satellite time in geomegnetic substorm envirenments.

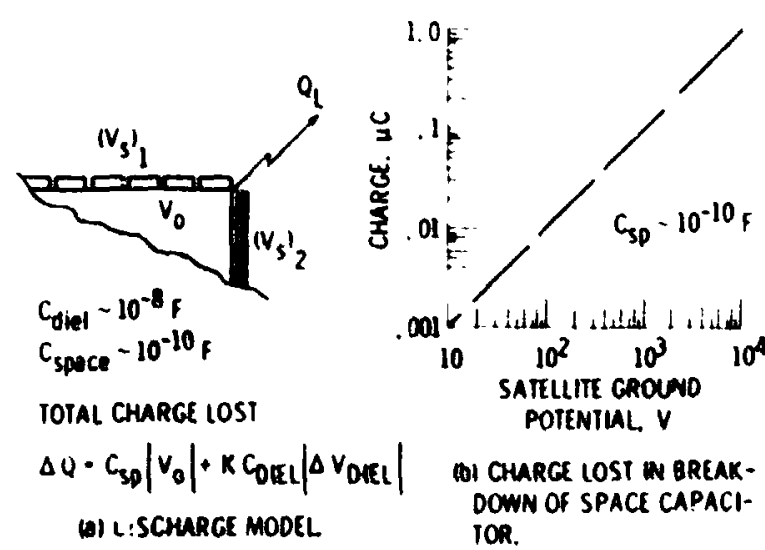

Flgure 2 - Surtace dischargex. 


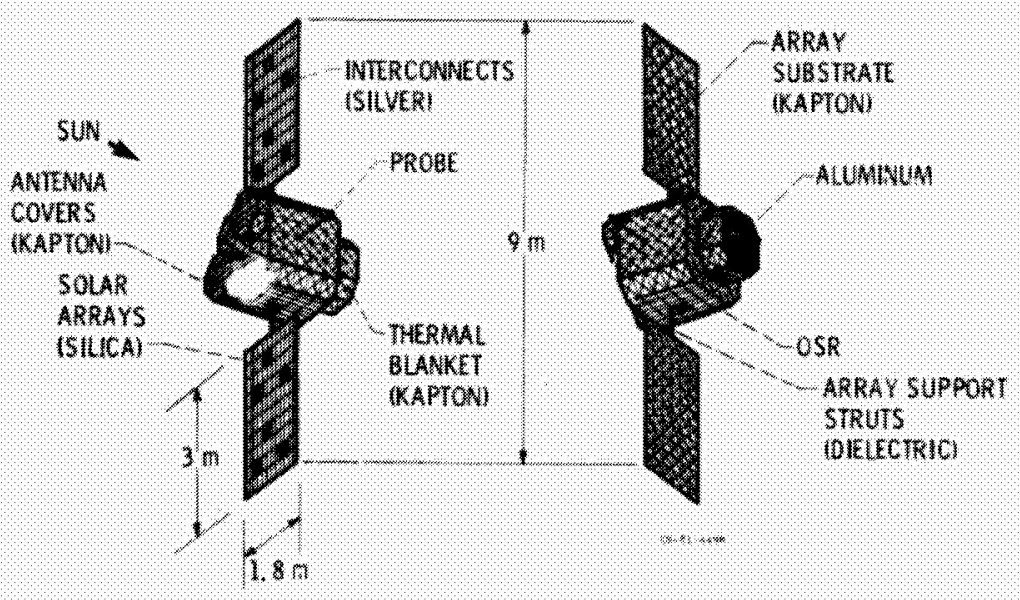

Figure 3 - mree-axis stabilized geosynchronous satellte - design guideline study.

THe, sec
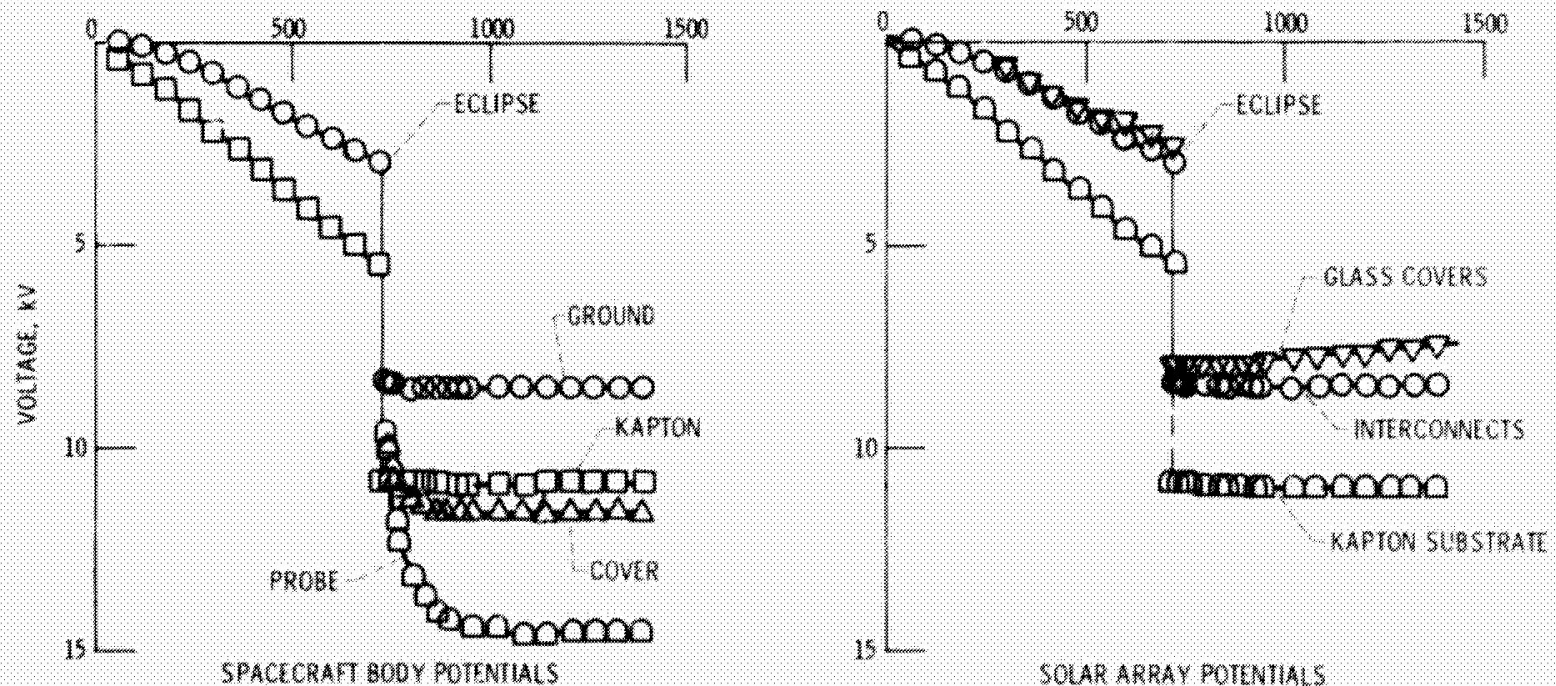

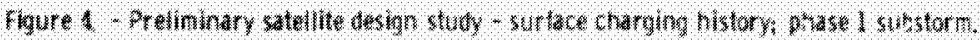



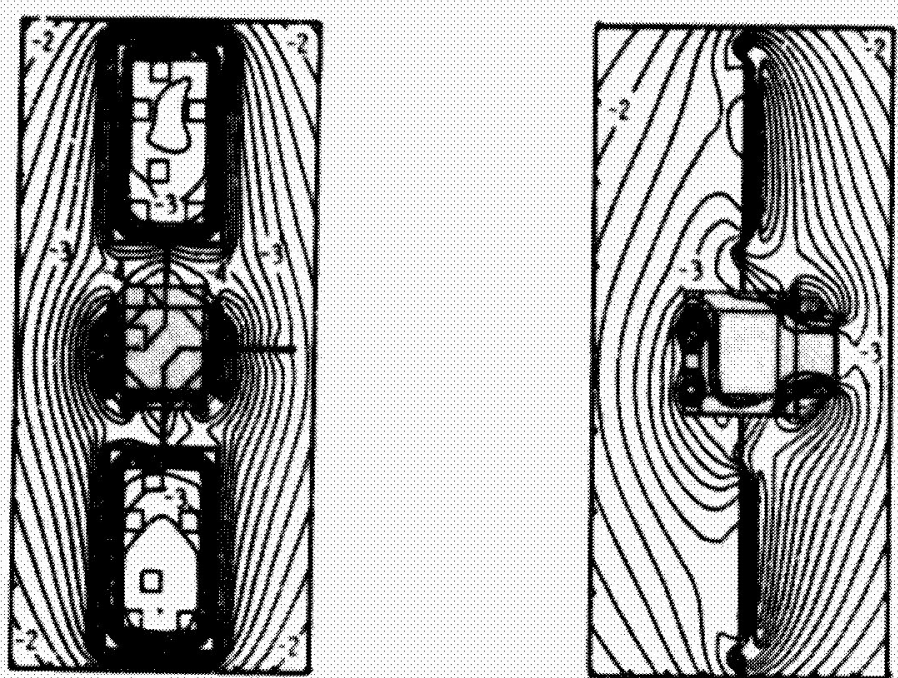

Fqure 5 - voltage prolles - sun charding equipolentials al a 2 WV spackcrat around $2 \mathrm{NW}$.

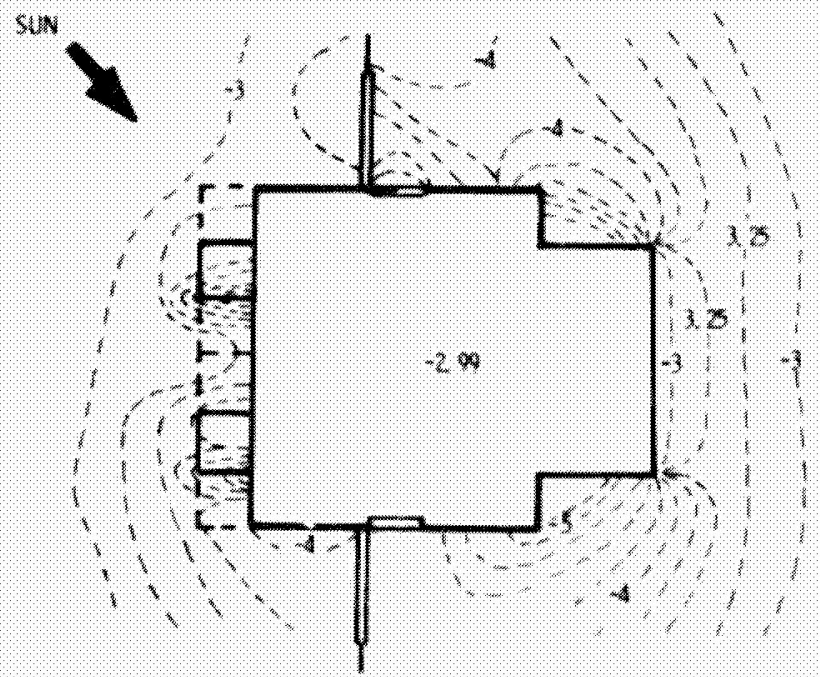

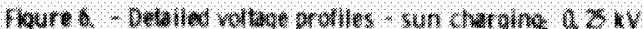

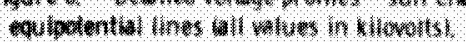



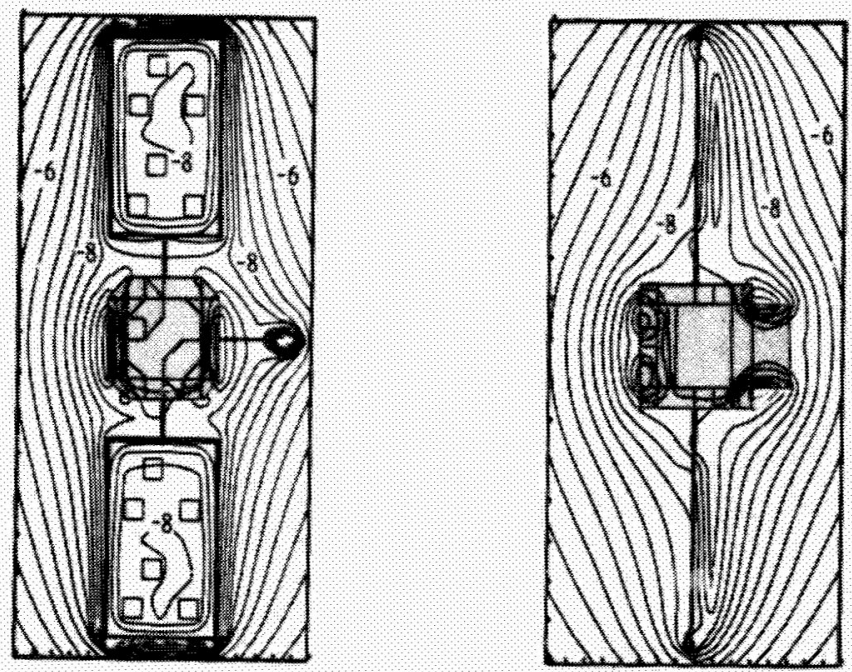

figure 7, - voliage profile - eclipse charging; satellite precharged; equipotentials at a $5 \mathrm{kV}$, spacecratt ground $-8.48 \mathrm{kV}$.
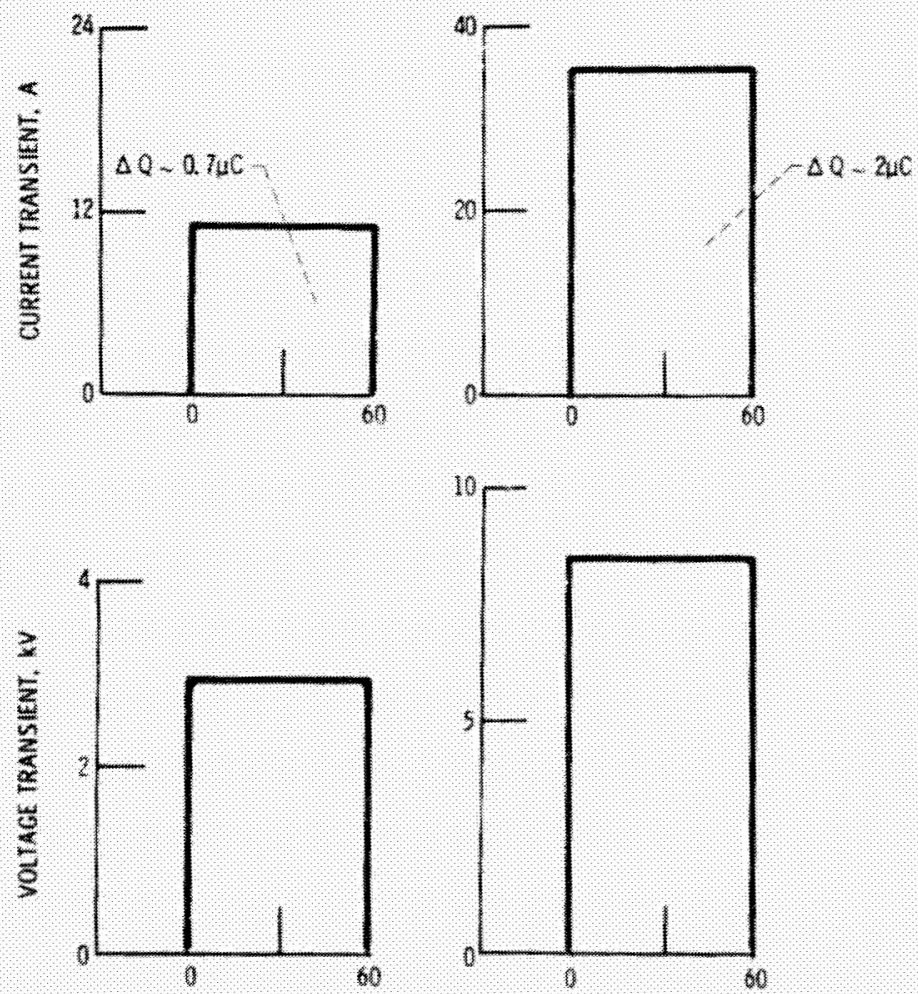

(a) SUNUGH CHARGWN conominows

TIME, nsec

D ECUPSE CHARGWG CONDIHONS

Figure \& - Antichated tischarge fulses. 

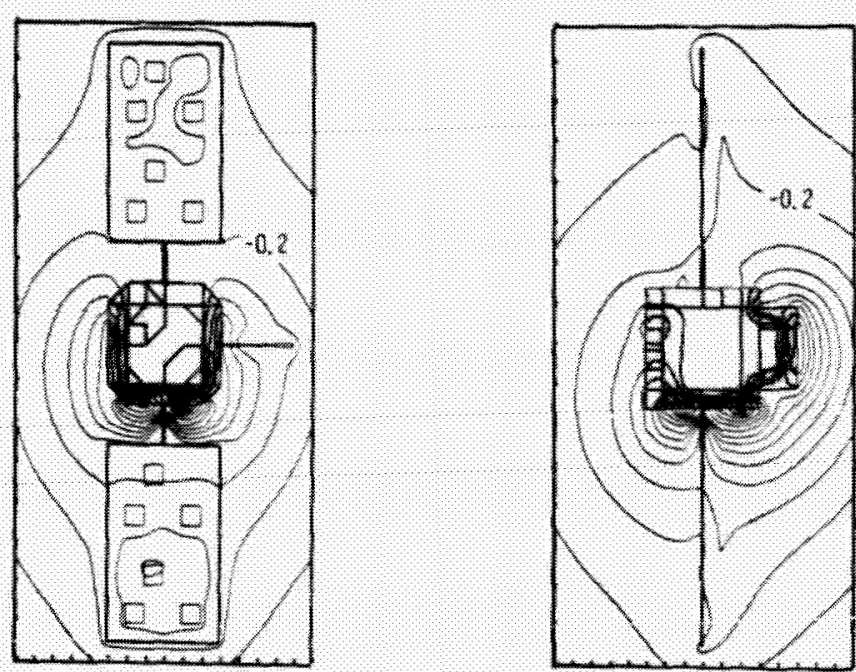

Figure 9 - Voltage protiles - sun charghn, phase I substom, materlals modi-

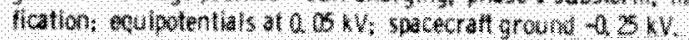

